|| Print ISSN: 2589-7837 || Online ISSN: 2581-3935 ||

International Journal of Medical Science and Diagnosis Research (IJMSDR)

Available Online at www.ijmsdr.com

NLM (National Library of Medicine ID: 101738824)

Original Research Article

Volume 6, Issue 2; February: 2022; Page No. 20-29

\title{
Effect of Maternal Body Mass Index on the Mode of Delivery and Neonatal Outcome: A Tertiary Care Hospital Based Study in Solan, Himachal Pradesh.
}

\author{
Dr Srishti Aggarwal ${ }^{1}$, Dr Manisha Behal ${ }^{2}$, Dr Neerja Singal ${ }^{3}$, Dr Santosh \\ Minhas $^{4}$, Dr. Sheetal Dagar 5 \\ 1,2,3,4,5 MMMC \& H, Solan
}

\section{Conflicts of Interest: Nil \\ Corresponding author: Dr Srishti Aggarwal \\ DOI: https://doi.org/10.32553/ijmsdr.v6i2.912}

\section{Abstract:}

Introduction: Obesity is a global health problem characterised as a pandemic issue by the World Health Organization (WHO), with a higher prevalence in females than males. During pregnancy, it is considered a high-risk state because it is associated with maternal complications like preeclampsia, gestational diabetes, obstetric interventions like caesarean delivery, postpartum haemorrhage; and fetal complications like macrosomia, poor apgar scores. BMI is a commonly used indicator which can be used to classify subjects on the basis of weight. Aim: This study aims to find the prevalence of normal weight, overweight and obese pregnant women defined by body mass index (BMI) according to the WHO classification and to study the associations between maternal BMI, the mode of delivery and neonatal outcome. Material and Methods: 200 pregnant women admitted for delivery in the department of Obstetrics \& Gynaecology were studied, height and weight were recorded from reliable antenatal records (recorded within two months of gestation). The Body Mass Index was calculated and patients were divided into four categories: Category I: underweight; Category II: normal BMI; Category III: Overweight; Category IV: Obese. The feto-maternal outcomes were studied. Results: On evaluation of 200 nulliparous antenatal women with singleton term gestation, 1.5\% were underweight, 33\% had normal BMI, 56\% were overweight and 9.5\% were obese. The prolongation of labour was seen in subjects with BMI more than $25 \mathrm{~kg} / \mathrm{m} 2$. Overweight patients had more instrumental deliveries and obese patients had a higher tendency for prolonged labour and caesarean deliveries. Neonatal outcomes were poor for obese and overweight patients as compared to normal BMI because more neonates required resuscitation at birth, had low Apgar scores and were small for gestational age. Maternal complications like Hypothyroidism, preeclampsia and gestational diabetes occurred more commonly in the obese category. Conclusion: In our institution, majority of patients were found to be overweight. Adverse perinatal outcomes were seen more often in the obese patients. Hence, obesity must be identified as a risk factor for adverse pregnancy outcomes.

Keywords: Body Mass Index, mode of delivery, neonatal outcome, obesity 


\section{Introduction:}

Obesity is a global health problem characterised as a pandemic issue by the World Health Organization (WHO), with a higher prevalence in females than males. It is associated with metabolic disease, nutritional deficiency, musculoskeletal complications and carcinomas.

Obesity is measured as a weight to height ratio and expressed as body mass index (BMI) most commonly. BMI is an internationally accepted and reliable way to assess obesity and related health problems. According to National Family Health Survey-4 ${ }^{\text {th }}$ report (NFHS-4) in Himachal Pradesh, $49.3 \%$ of non-pregnant women of age group 20-39 years had BMI $\geq 25$ and $11.4 \%$ had BMI $\geq 30$. In Solan district according to this report $32.7 \%$ of women of $15-49$ years age group had BMI $\geq 25$.

Body mass index is a quotient that has been in use since the mid-19th century. The BMI, or Quetelet index, is a heuristic proxy for human body fat based on an individual's weight and height. It was devised between 1830 and 1850 by the Belgian polymath Adolphe Quetelet during the course of developing "social physics". ${ }^{2}$ It is universally expressed in $\mathrm{kg} / \mathrm{m}^{2}$. It is used for classification of individuals as follows:

\begin{tabular}{|c|c|}
\hline Underweight & BMI value less than $18.5 \mathrm{~kg} / \mathrm{m}^{2}$ \\
\hline Normal BMI & BMI value between $18.5-24.9 \mathrm{~kg} / \mathrm{m}^{2}$ \\
\hline Overweight & $\mathrm{BMI}>25 \mathrm{~kg} / \mathrm{m}^{2}$ \\
\hline Pre-Obese & BMI greater than or equal to 25 to $29.9 \mathrm{~kg} / \mathrm{m}^{2}$ \\
\hline Obesity & BMI greater than or equal to $30 \mathrm{~kg} / \mathrm{m}^{2}$ \\
\hline i. $\quad$ Obesity class I & BMI 30 to $34.9 \mathrm{~kg} / \mathrm{m}^{2}$ \\
\hline ii. Obesity class II & BMI 35 to $39.9 \mathrm{~kg} / \mathrm{m}^{2}$ \\
\hline iii. $\quad$ Obesity class III & BMI greater than or equal to $40 \mathrm{~kg} / \mathrm{m}^{2}$ \\
\hline
\end{tabular}

The obesity-related health issues extend to pregnancy and are often responsible for producing a variety of medical and obstetric complications resulting in an increase of maternal and fetal morbidity and mortality. As compared to normal-weight patients, obese patients have a higher prevalence of infertility. Once they conceive, they have higher rates of early miscarriage and congenital anomalies, including neural tube defects. Besides the coexistence of preexisting diabetes mellitus and chronic hypertension, obese women are more likely to have pregnancy-induced hypertension, gestational diabetes, thrombo-embolism, macrosomia, and spontaneous intrauterine demises in the latter half of pregnancy. Obese women also require instrument or Caesarean section delivery more often than average-weight women. ${ }^{3}$

The aim of our study is to investigate the effect of the maternal BMI on the mode of delivery and the neonatal outcome in the deliveries that take place in Maharishi Markandeshwar medical college and hospital, Solan.

\section{Material and methods}

Our study was an observational crosssectional study, conducted in the department of Obstetrics and Gynaecology, Maharishi Markandeshwar Medical College and Hospital, Solan, Himachal Pradesh. Informed written consent was taken for all patients participating in the study. The study was carried out for a duration of 18 months after clearance from Institutional Ethical Committee. After considering below mentioned inclusion and exclusion criteria, 200 pregnant women who were admitted in the department of Obstetrics \& Gynaecology for delivery during the study period were considered for the study. 


\section{Inclusion criteria:}

1. Gestational age $\geq 37$ completed weeks at the time of newborn birth

2. Singleton pregnancy

3. Reliable documented record of maternal weight in antenatal record history of any Primary health care centre/Community health centre/Hospital/Private Clinic (within 2 months of last menstrual period)

\section{Exclusion criteria:}

1. History of previous caesarean

2. Multiple gestation

3. $<18$ years or $>35$ years maternal age

4. Chronic renal/respiratory/cardiac or neurological disease

5. Pre-existing diabetes or hypertension

6. Patients who achieved the pregnancy by Artificial Reproductive Techniques (ART) or Intrauterine Insemination (IUI)

7. Short stature (Maternal height less than $145 \mathrm{~cm})$
8. Abnormal lie/Malpresentation of fetus at the time of delivery

9. Congenital malformations in newborn

After detailed history and examination, reliable maternal weight which was documented in antenatal record history of within 2 months of last menstrual period was taken and height (in metres) was measured using a stadiometer. The data was used to calculate the BMI using the standard formula.Patients were then divided into 3 groups: BMI 18.5- 24.9 $\mathrm{kg} / \mathrm{m}^{2}$; BMI $25-29.9 \mathrm{~kg} / \mathrm{m}^{2}$ and BMI $>30$ $\mathbf{k g} / \mathbf{m}^{2}$ In these groups, feto-maternal outcome was studied.

\section{Results}

It was observed that out of the 200 patients included in the study, most were overweight patients $(112,56 \%)$ with BMI 25 $29.99 \mathrm{~kg} / \mathrm{m}^{2}$ followed by those with normal BMI $\left(18-24.99 \mathrm{~kg} / \mathrm{m}^{2}\right) \quad(69,33 \%), 19$ patients were obese $(9.5 \%)$ and only 3 $(1.5 \%)$ were found to be underweight in the study.

\section{Distribution based on body mass index $\left(\mathrm{kg} / \mathrm{m}^{2}\right)$ of study subjects}

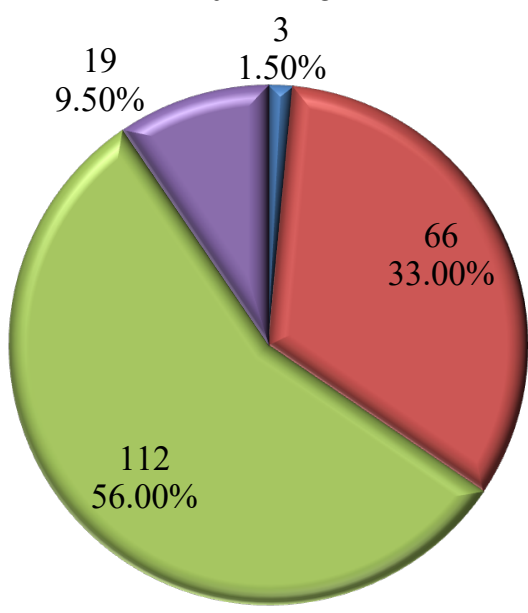

口Underweight $\left\{<18 \mathrm{~kg} / \mathrm{m}^{2}\right\} \quad$ Normal $\left\{18\right.$ to $\left.24.99 \mathrm{~kg} / \mathrm{m}^{2}\right\}$

四Overweight $\left\{25\right.$ to $\left.29.99 \mathrm{~kg} / \mathrm{m}^{2}\right\} \quad$ 四Obese $\left\{>=30 \mathrm{~kg} / \mathrm{m}^{2}\right\}$

Figure 1: Distribution of body mass index $\left(\mathrm{kg} / \mathrm{m}^{2}\right)$ of study subjects. 
The majority of patients belonged to the overweight category $(56 \%)$ followed by those with normal BMI (33.0\%), depicting a shift in the weight categories towards increasing BMI.

The average BMI was $25.72 \pm 3.20 \mathrm{~kg} / \mathrm{m}^{2}$. The average age of the patients was $26.66 \pm 4.3$ years with no significant difference.

Table 1: Educational status

\begin{tabular}{|l|l|l|l|l|l|l|}
\hline Educational status & $\begin{array}{l}\text { Underweight } \\
(<\mathbf{1 8})\end{array}$ & $\begin{array}{l}\text { Normal } \\
\mathbf{( 1 8 - 2 4 . 9 9 )}\end{array}$ & $\begin{array}{l}\text { Overweight } \\
(\mathbf{2 5 - 2 9 . 9 9 )}\end{array}$ & $\begin{array}{l}\text { Obese } \\
(\mathbf{3 0} \text { or more) }\end{array}$ & Overall & $\begin{array}{l}\text { P } \\
\text { value }\end{array}$ \\
\hline 10th or below & $\mathbf{2}$ & 20 & 17 & 3 & 42 & 0.075 \\
& $\mathbf{( 6 6 . 6 7 \% )}$ & $(30.30 \%)$ & $(15.17)$ & $(15.78)$ & $(21 \%)$ & \\
\hline Grad/Post Grad & 0 & 22 & 37 & 8 & 67 & \\
& $(0 \%)$ & $(33.33 \%)$ & $(33.03)$ & $(42.10)$ & $(33.50 \%)$ & \\
\hline Up to 12th & 1 & 24 & 58 & 8 & 91 & \\
& $(33.3 \%)$ & $(36.36 \%)$ & $(51.78)$ & $(42.10)$ & $(45.50 \%)$ & \\
\hline Overall & $\mathbf{3}$ & $\mathbf{6 6}$ & $\mathbf{1 1 2}$ & $\mathbf{1 9}$ & $\mathbf{2 0 0}$ & \\
\hline
\end{tabular}

It was seen that the proportion of patients with education up to $12^{\text {th }}$ or $\mathrm{grad} /$ post grad was significantly higher in the overweight and obese category compared to those with normal BMI.

The highest percentage of underweight patients had an educational status of $10^{\text {th }}$ standard or below. The monthly family income was comparable in all the four groups, being marginally higher in the obese and underweight categories, statistically insignificant.

\section{Mode of delivery}

Overall, LSCS rate was $25.50 \%$. Patients with higher BMI had higher proportion of patients with LSCS $(52.63 \%$ in obese patients, $28.57 \%$ in overweight patients, $13.64 \%$ with normal BMI) and 0 for underweight category. The difference was found to be statistically significant $(\mathrm{p}=0.008)$.

Figure 2: Association of mode of delivery with BMI

\section{Association of mode of delivery with body mass index}

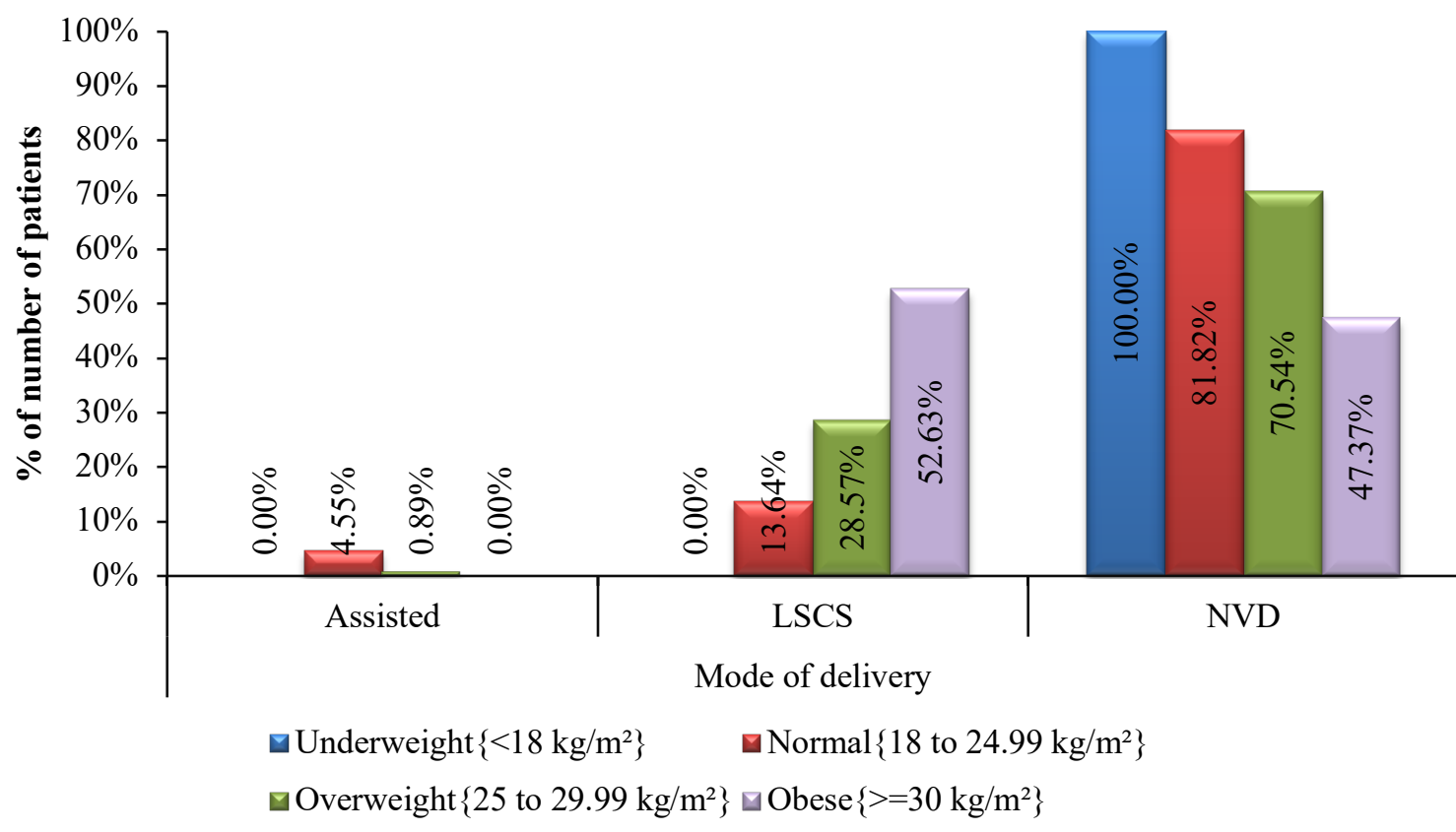


The most common LSCS indication was fetal distress $(28,54.90 \%)$ followed by failed induction $(13,25.49 \%)$. The patients in the obese category underwent caesarean for failed induction $(50 \%)$ and fetal distress $(50 \%)$, with none having the indication of arrest of labour.

\section{Labour characteristics}

Patients with BMI more than 30 had a higher proportion of patients with absent fetal membranes $(26.32 \%$ vs $10.61 \%$ and $10.71 \%)$. The difference however was significant statistically with $\mathrm{p}=0.02$.

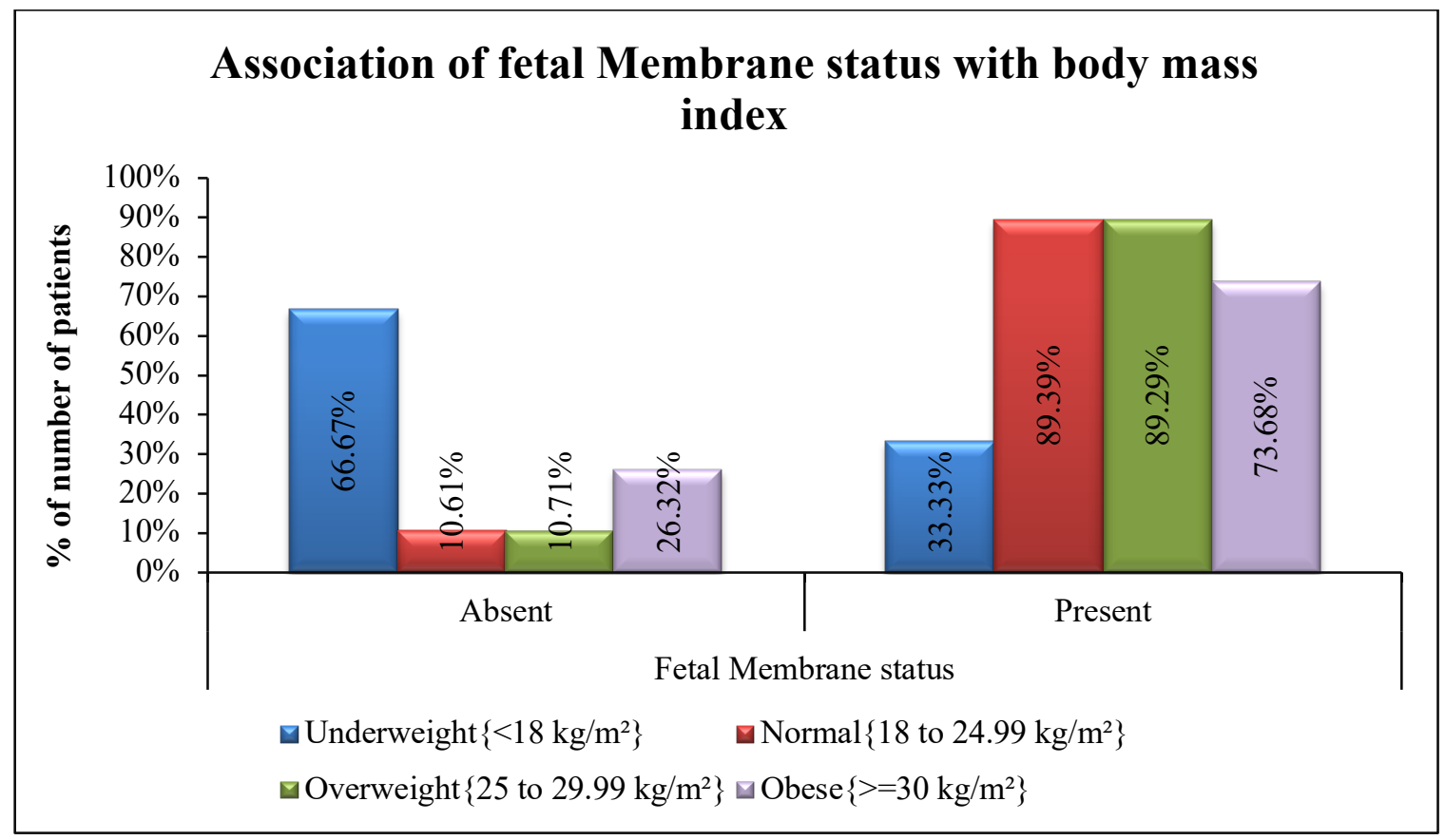

Figure 3: Association of membrane status with body mass index.

The proportion of subjects with meconium-stained liquor was significantly higher in the obese patients (36.85\%) compared to overweight (9.83\%) and normal BMI patients $(13.04 \%)$.

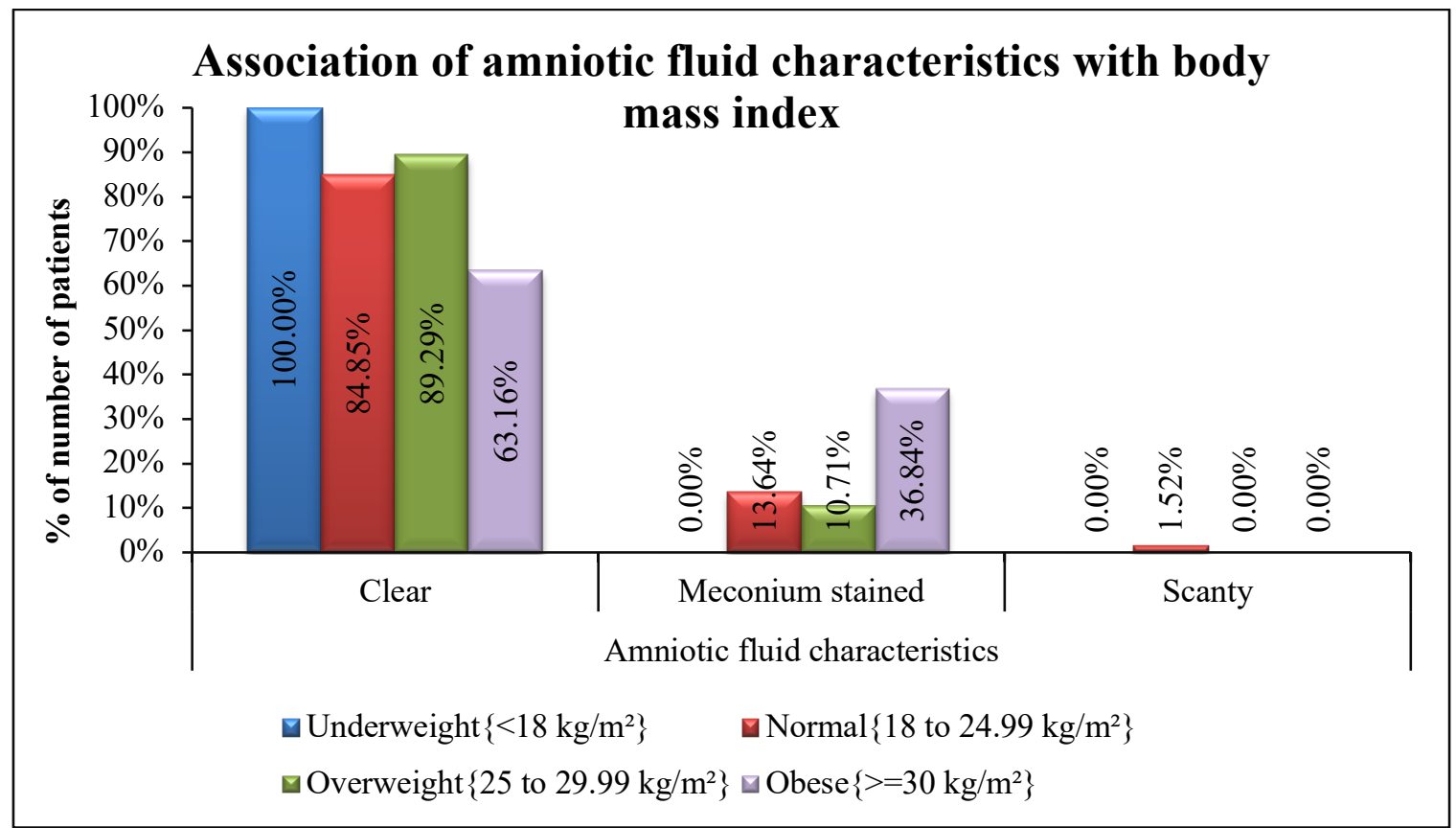

Figure 4: Association of amniotic fluid characteristics with body mass index. 
The average duration of first stage of labor was highest in the overweight group (10.52 hours, $\mathrm{p}=0.008$ ) among all four categories. The average second stage duration (22.04 minutes) was higher for the normal BMI group of patients compared to the overweight and obese patients. Hence, average duration of labour was found to be higher in the overweight category followed by normal BMI category.

Table 2: Duration of stages of labour

\begin{tabular}{|l|l|l|l|l|l|l|}
\hline Labour duration & $\begin{array}{l}\text { Underweight } \\
\mathbf{( < \mathbf { 1 8 } )}\end{array}$ & $\begin{array}{l}\text { Normal } \\
\mathbf{( 1 8 - 2 4 . 9 9 )}\end{array}$ & $\begin{array}{l}\text { Overweight } \\
\mathbf{( 2 5 - 2 9 . 9 9 )}\end{array}$ & $\begin{array}{l}\text { Obese } \\
\mathbf{( 3 0} \text { or more) }\end{array}$ & Overall & $\begin{array}{l}\mathbf{P} \\
\text { value }\end{array}$ \\
\hline Number of patients & $\mathbf{n = 3}$ & $\mathbf{n = 5 7}$ & $\mathbf{n = 8 0}$ & $\mathbf{n = 9}$ & $\mathbf{1 4 9}$ & \\
\hline $\begin{array}{l}\text { Average first stage } \\
\text { (in hours) }\end{array}$ & 7.03 & 9.05 & $\mathbf{1 0 . 7 2}$ & 9.0 & 9.90 & $\mathbf{0 . 0 0 8}$ \\
\hline $\begin{array}{l}\text { Average second stage } \\
\text { (in minutes) }\end{array}$ & 19 & $\mathbf{2 2 . 0 4}$ & 20.95 & 15.56 & 21.00 & 0.081 \\
\hline $\begin{array}{l}\text { Average third stage } \\
\text { (in minutes) }\end{array}$ & 2.67 & $\mathbf{3 . 5 1}$ & 2.96 & 3.44 & 3.19 & $\mathbf{0 . 0 0 2}$ \\
\hline
\end{tabular}

\section{Maternal outcome}

The proportion of patients with maternal complication was significantly higher in the overweight and obese group of patients $(\mathrm{P}=0.001)$.

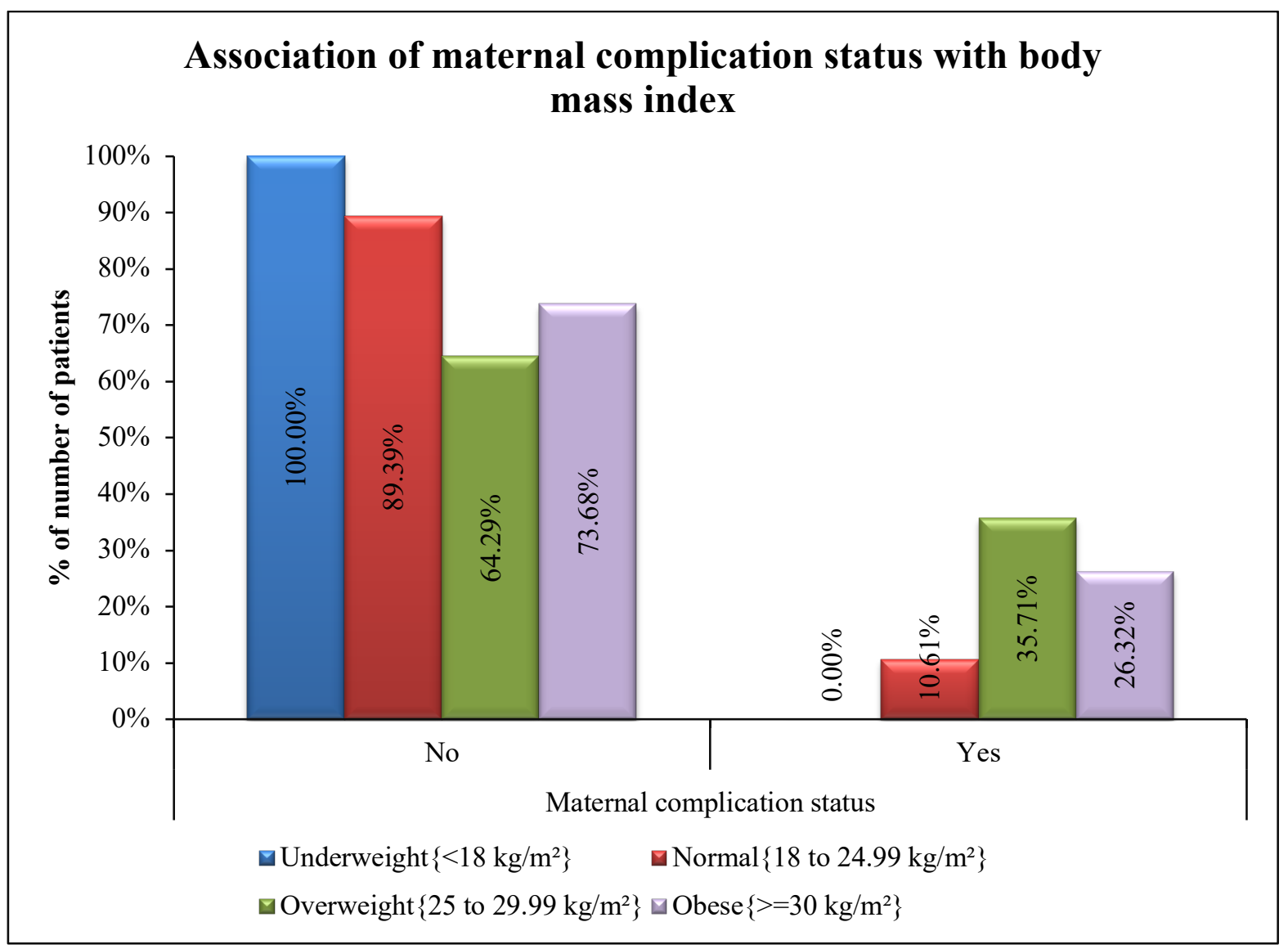

Figure 5: Association of maternal complication status with body mass index. 


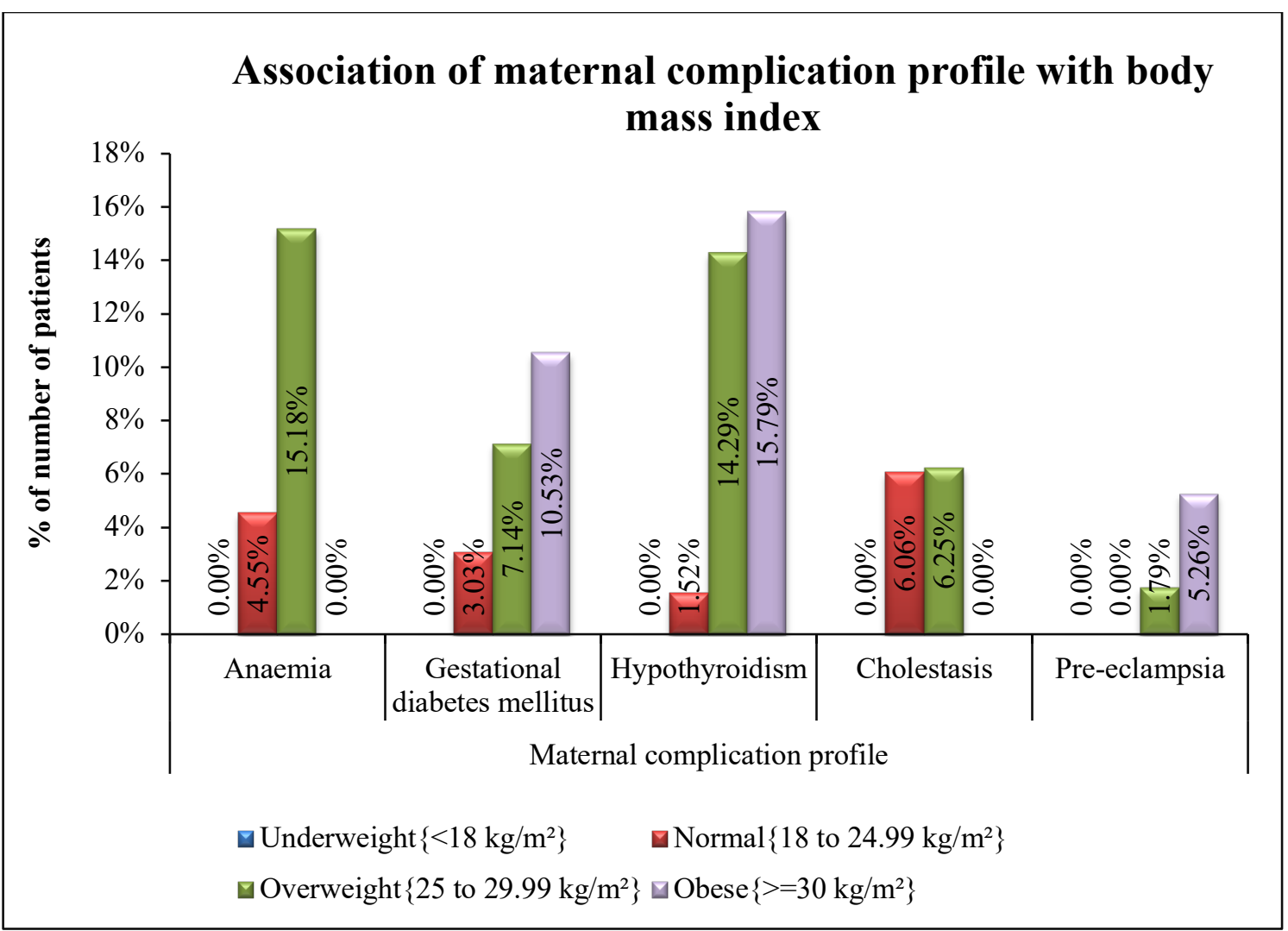

Figure 6: Association of maternal complication profile with body mass index.

The proportion of hypothyroidism was higher in patients with BMI greater than 25 $\mathrm{kg} / \mathrm{m} 2$. This difference was significant statistically $(\mathrm{P}=0.014)$. The occurrence of gestational diabetes mellitus and preeclampsia were the highest in the obese category with BMI $>30 \mathrm{~kg} / \mathrm{m}^{2}$.

\section{Fetal outcome}

The proportion of patients with APGAR less than 7 at 1 minutes was higher in the obese group of patients $(10.52 \%)$ and APGAR less than 7 at 5 minutes was higher in the overweight group $(1.79 \%)$. Both were statistically insignificant.

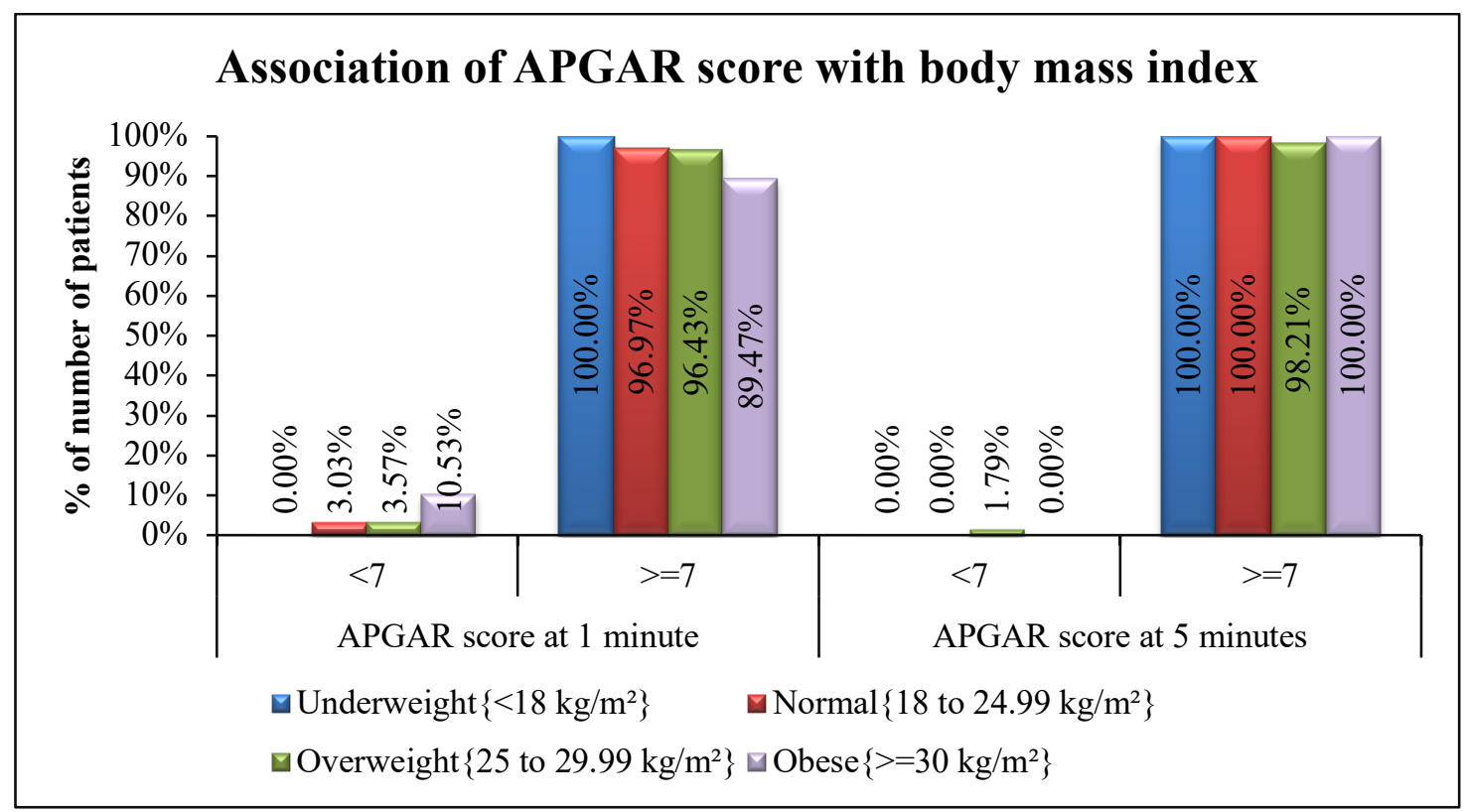

Figure 7: Association of APGAR score with body mass index. 
A higher proportion of patients in the obese group were either small for gestational age or large for gestational age compared to the other groups. The difference was found to be statistically significant $(\mathrm{P}=0.045)$.

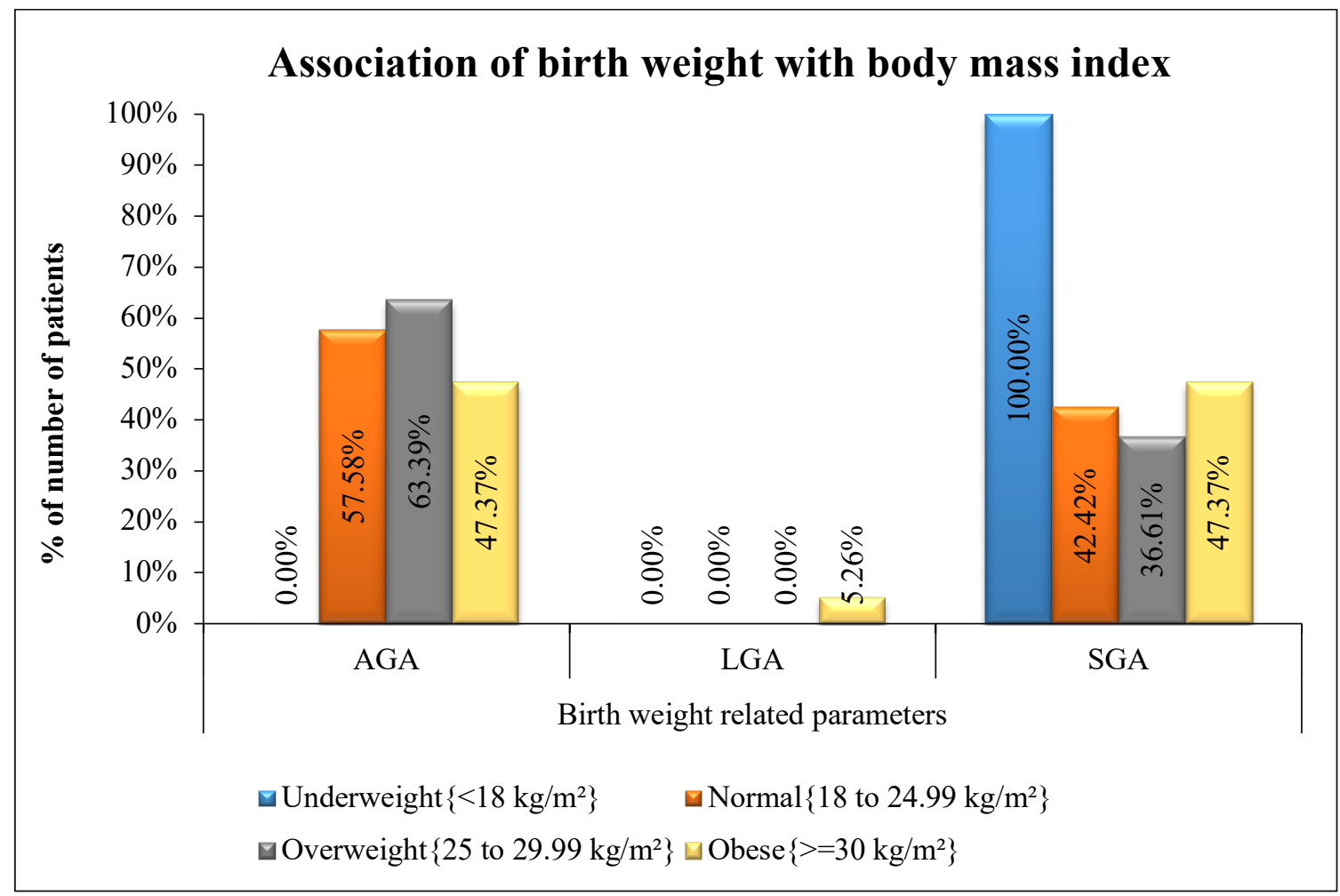

Figure 8: Association of birth weight with body mass index.

\section{Discussion}

Obese women have been associated with higher risk of developing gestational diabetes mellitus, gestational hypertension, preeclampsia, venous thromboembolism, postpartum haemorrhage, caesarean delivery, and maternal death. With this background, we planned and conducted this study on 200 pregnant females in the Department of Obstetrics \& Gynaecology in Maharishi Markandeshwar Medical College and Hospital, Kumarhatti, Solan. We evaluated the effect of Body mass Index on the mode of delivery and various fetomaternal outcomes in our setup. It was seen that out of the 200 patients included in the study, most were over-weight patients (112, $56 \%$ ) with BMI $25-29.99 \mathrm{~kg} / \mathrm{m}^{2}$ followed by those with normal BMI (18-24.99 $\left.\mathrm{kg} / \mathrm{m}^{2}\right)(69,33 \%)$. Only 19 obese patients $(9.5 \%)$ and 3 underweight $(1.5 \%)$ were seen in the study. The average BMI was $25.72 \pm 3.20 \mathrm{~kg} / \mathrm{m}^{2}$.

Dsouza et al (2019) in an Australia based study showed that over $50 \%$ of women were overweight or obese and $5.2 \%$ of mothers were found to be in the morbidly obese category. 4

Vanlalfeli et al (2020) reported that the mean age was $23 \pm 3.53$ among normal BMI patients and $25 \pm 4.44$ among obsess patients. The observations related to the patients age were similar to that seen in our study. ${ }^{5}$

Overall, the study population had LSCS rate of $25.50 \%$. Patients with higher BMI had higher proportion of patients with LSCS $(52.63 \%$ in obese patients, $28.57 \%$ in overweight patients and $13.05 \%$ with normal BMI). The risk of caesarean sections and instrumental deliveries was also seen to rise significantly with increase 
in BMI $(p=0.002)$ in a similar study by Bhushan et al (2017). ${ }^{6}$ The most common LSCS indication was failed induction (10, $5 \%$ ) followed by acute fetal distress (9, $4.5 \%)$. It is crucial to understand if the increased rate of caesarean is secondary to a likely increase in the fetal weight or is result for some other underlying mechanism not fully understood yet.

Chu SY et al (2007) in their meta-analysis on 33 studies showed that the risk for caesarean delivery was higher among overweight, obese, and severely obese women compared with normal weight pregnant women. The risk was almost $60 \%$ to $190 \%$ more compared to the reference category. ${ }^{7}$

In our study, fifty-two patients (26\%) experienced a maternal complication. The proportion of patients with maternal complication was found to be significantly higher in the overweight and obese group of patients $(\mathrm{P}=0.001)$. Similarly, in the study by Bhushan et al (2017), the risk of antepartum complications like GDM and pre-eclampsia increased significantly with the increase in BMI with $p$ values of 0.02 and 0.001 respectively. ${ }^{6}$

A Turkish study by Calik et al (2018) showed that the rate of caesarean, instrumental delivery, induction, episiotomy, late breastfeeding, low Apgar $(<7$ at $5 \mathrm{~min})$, neonatal intensive care unit admission requirement, the new-born at $4000 \mathrm{~g}$ or more in overweight (BMI 25$29.9)$ and obese $(B M I \geq 30)$ pregnancies was higher and the first and second phases of labor were longer $(p<0.05)$. The duration of first stage was similar and second stage was seen to be lower in our study. ${ }^{8}$

Prabha Kumari et al (2014) in her Delhi based study showed a linear relationship between increasing BMI and the risk of developing preeclampsia, gestational diabetes mellitus, failed induction of labor, caesarean section, both elective and emergency, postpartum haemorrhage, abnormal birth weight and neonatal intensive care unit admission. ${ }^{9}$

\section{Conclusion}

The study depicts the increasing prevalence of overweight and obese women in the region of Himachal Pradesh. The higher association of maternal complications is usually seen with obesity in pregnant women. Neonatal complications like poor APGAR score and low birth weight were also more common in the categories with BMI more than $25 \mathrm{~kg} / \mathrm{m}^{2}$. The current scenario calls for spreading awareness about obesity in order to prevent the adverse effects associated.

Hence we conclude that a better understanding of the pathophysiological link between obesity and the various adverse outcomes of pregnancy described in our study is needed before prevention and management strategies can be devised. This study provides vital information to facilitate prepregnancy and early pregnancy counselling to encourage appropriate interventions to improve outcomes for mothers and babies.

\section{References}

1. Liu L, Ma Y, Wang N, Lin W, Liu Y. Maternal body mass index and risk of neonatal adverse outcomes in China: a systematic review and meta-analysis. BMC Preg Childbirth 2019; 19:105-9.

2. Bhuyar S, Dharmale N. Effect of maternal body mass index on pregnancy outcomes. International Journal of Reproduction, Contraception, Obstetrics and Gynecology, [S.1.], 2018; 12(7): 4949-55.

3. Fitzsimons KJ, Modder J, Greer IA. Obesity in pregnancy: risks and management. Obstet Med. 2009; 2 (2):52-62.

4. D'Souza R, Horyn I, Pavalagantharajah S, Zaffar N, Jacob CE. Maternal body mass index and pregnancy outcomes: a systematic review and metaanalysis. Am J Obstet Gynecol MFM. 2019; 1(4):100041. 
5. Vanlalfeli, Zosangpuii. Study of maternal and fetal outcome in obesity complicating pregnancy. Int J Contemp Med Res 2020;7(2):B1-B5.

6. Bhushan N, Surinder K, Dinesh K, Khajuria R. The impact of maternal body mass index on maternal and perinatal outcome. Int $\mathrm{J}$ Reprod Contracept Obstet Gynecol 2017; 6: 2862-6.

7. Chu SY, Callaghan WM, Kim SY, et al. Maternal obesity, and risk of gestational diabetes mellitus. Diabetes Care. 2007; 30: 2070-76.

8. Çalik KY, Yildiz NK, Erkaya R. Effects of gestational weight gain and body mass index on obstetric outcome. Saudi journal of biological sciences. 2018; 25(6): 1085-9.

9. Kumari P, Gupta M, Kahlon P, Malviya S. Association between high maternal body mass index and feto-maternal outcome. J Obes Metab Res 2014;1:143-8. 